\title{
The Capacity of Discrete Parts to Form Continuous Assemblages
}

KORY BIEG

University of Texas at Austin

Watney is a design-build, mobile installation composed of an assemblage of discrete parts. Each part has its own logic and properties and each combines to form a whole that both affects and is affected by the parts. The project represents a new type of machine; it is a continuous assemblage in which formal continuity is the constraint that ties otherwise independent parts into a collective as opposed to an aggregation of self-similar units or a hierarchically bound composite in which the whole is somehow greater than the parts. The project as a whole engages the site through formal and cultural relations that are both familiar and unfamiliar to the place, eliciting new revelations of both site and object.

Watney is one local manifestation of a fully parametric digital model which includes other potential manifestations. A particular iteration was selected based on its ability to be fabricated using CNC processes, the effect of each part's properties on the whole, and the constraints imposed by the whole on each part in order to achieve a continuous assemblage. The selection process was guided by the relationship between parts and whole and by contextual cues that promoted some versions over others.

Watney also provides a new take on the waffle rib structure system. By treating each part as an independent, self-structuring, uniquely formal object, Watney disentangles the parts from a top-down structural scheme. The resultant assembly of multidirectional waffles contained by the surface of each part produces a whole that is much stronger than one created using a conventional rib system. Furthermore, the manifestation of each part's particular structural solution is, like the object itself, guided by an internal logic that relates to other properties of the part in which it is contained. Each part is guided by conditions imposed by the whole and by contextual cues, such as occupation, view, and environmental and cultural responsiveness.

WATNEY: A HYPEROBJECT

The project was named Watney after the character Mark Watney from the film the Martian ${ }^{1}$. In the movie, Watney is a botanist and astronaut sent to Mars who is left stranded after an accident and must design a variety of tools to keep himself alive long enough for mission control to find a way to bring him home. While Watney waits alone on Mars, news of his survival and the rescue operation blossoms into a cultural movement on earth. Watney becomes what Timothy Morton calls a hyperobject. A hyperobject, according to Morton is an object that is "massively distributed in time and space [and] nonlocal."2

An example he gives of a Hyperobject is the nuclear bomb. The bomb is more than a singular object; it includes an assemblage of many other things such as its affect on the physical world, everything that goes into its development (resources, energy, and capitol), and how one's awareness of the potential devastation of the bomb impacts one's behavior. ${ }^{3}$

Watney grows into a hyperobject based on the ethos surrounding his survival and retrieval from Mars. His predicament mobilizes social media, and people's behavior changes in response. They become implicitly invested in his safe return, even though they have no control over the outcome and in spite of the fact that they have no direct contact with him. Society galvanizes around the epic nature of Watneys journey to the point that his story becomes a cultural movement and transcends the individual himself.

Like the character, our project Watney is a hyperobject. The project as a whole engages site and context through formal and cultural relations that are both familiar and unfamiliar to the place, drawing people to the object and inviting them to engage with it. The object is a kind of hyperobject that influences more than itself through a dynamic set of relations. The project is also an assemblage of discrete parts, each part with its own logic and properties, which combine to form a whole. 


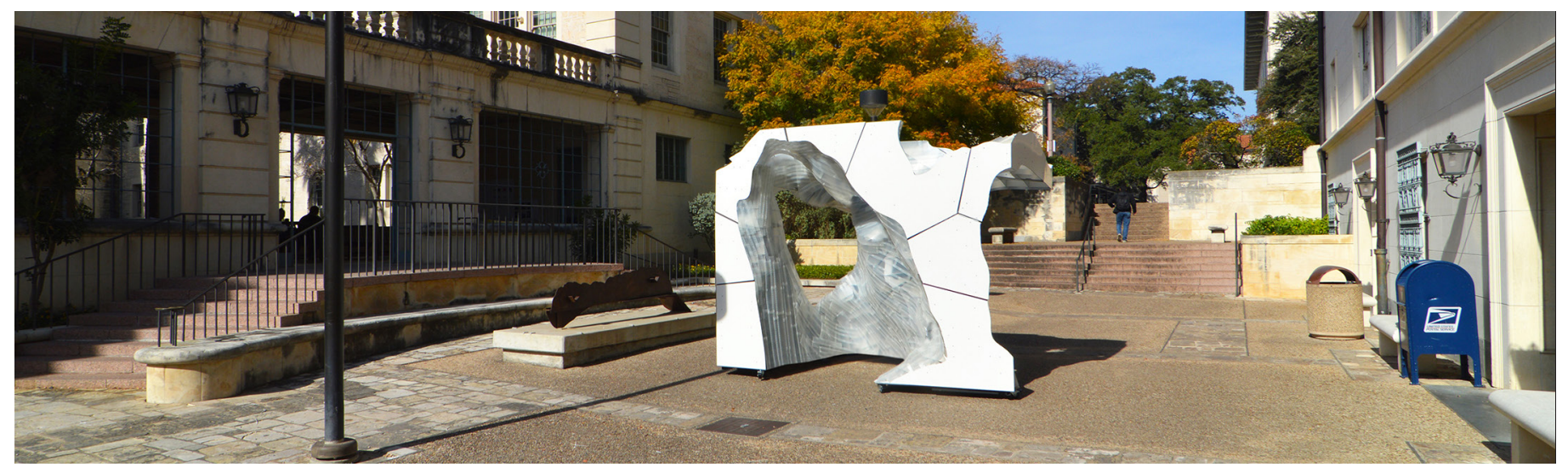

Figure 1: Watney at The University of Texas at Austin School of Architecture, Goldsmith Courtyard.

\section{PART TO WHOLE}

The part to whole ethos is not new and has been a central polemic of architectural discourse for generations. Though there have been many categorical definitions of part to whole relations that have influenced design and architecture, Organicism, Reductionism and Mechanism are three of the most prevalent views.

In Organicism, the whole is greater than the parts. Organicism favors the body over the composition and the value of the whole limits the significance of parts. Though parts might possess the capacity to be other, they operate and exist only as directed by and for the needs of the whole.

In his essay On Numbers, More or Less, Reinhold Martin refers to Parametricism as a kind of Organicism. For Martin, Parametricism is a form of Organicism "because it encodes a nightmarishly emergent, autopoietic system that is fiendishly alive [on our society]...life itself is subject to the tyranny exerted by numbers when conceived as instruments rather than thoughts." ${ }^{4}$ This view of Parametricism suggests that we relinquish our control over design to whatever limits are determined by the parametric model. The ability to interfere at the level of part is greatly reduced and the part itself is only allowed to express values (both numerical and ethical) imposed by the larger ordering system.

The second part to whole logic is Reductionism. As opposed to Organicism, Reductionism favors the parts over the whole. Reductionism reduces everything to its smallest part and in some cases down to atoms. As is the case with swarm logic, the behavior of the whole is determined entirely by the parts. Graham Harman would call this undermining. For Harman, "undermining occurs...when individuation matters more than the autonomy of fully formed individuals. ${ }^{\prime 5}$ Undermining in architecture occurs when we assign value to projects based on criteria that have little to do with the building as a designed object. Mark Foster Gage gives the example of LEED Certification: "To know that a building is LEED-Certified is to know that it was built with certain types of sustainable components and systems that it presumes use less energy than those that are not LEED certified. The architectural qualities of a building-as-object, then, are disregarded in favor of its sustainable parts. Cloaked in a cape of friendly sustainability, LEED certification has irreparably changed the public's understanding of architecture. ${ }^{6}$ Reductionism places such a large distance between part and whole, that whole is almost irrelevant.

The philosophy of Mechanism shares some similarities with Reductionism in that parts are favored over, though not entirely reduced from, the whole. In mechanism, wholes are simply the aggregation of parts and the behavior of the whole is just the working and external influence of the parts, like a machine. Rene Descartes advocated a mechanistic approach to understanding natural phenomenon. In Treatise for Man, Descartes equated the function of the body with the gears of a machine. He argued that the human's function "follows from the mere arrangement of organs every bit as naturally as the movements of a clock or other automation follow from the arrangement of its counter-weights and wheels."7 The whole is dependent on the parts, so much so that if a part is removed, the whole would cease to be.

\section{OBJECT ORIENTED ONTOLOGY}

Recent contributions of Object Oriented Ontology (OOO) have placed a renewed interest in how part to whole relationships might guide - in both practice and theory - new methodologies for architectural design via a new approach to part to whole logic. 000 is a flat ontology in which all objects are equal. As video game designer and theorist, lan Bogost, puts it, "An ontology is flat if it makes no distinction between the types of things that exist but treats all equally." 8 Both the whole and the objects in the whole are objects in their own right. There is no hierarchy of importance between objects. Each object has its own unique and intrinsic properties, and these qualities of the object are withdrawn from the object's expression of them and how they are affecting and being affected by other objects.

Though all objects are equal, all objects are not the same. This would be another form of undermining, because doing so would suggest that since a turtle and a torch can be reduced to atoms, they are the same, when in fact they are different and each have their own set of expressed and withdrawn conditions. And though objects are not the same and are withdrawn from one another, they are also not entirely independent. As Harman notes, "In the environment, all objects gain their meaning only in relations with one another. Everything belongs 


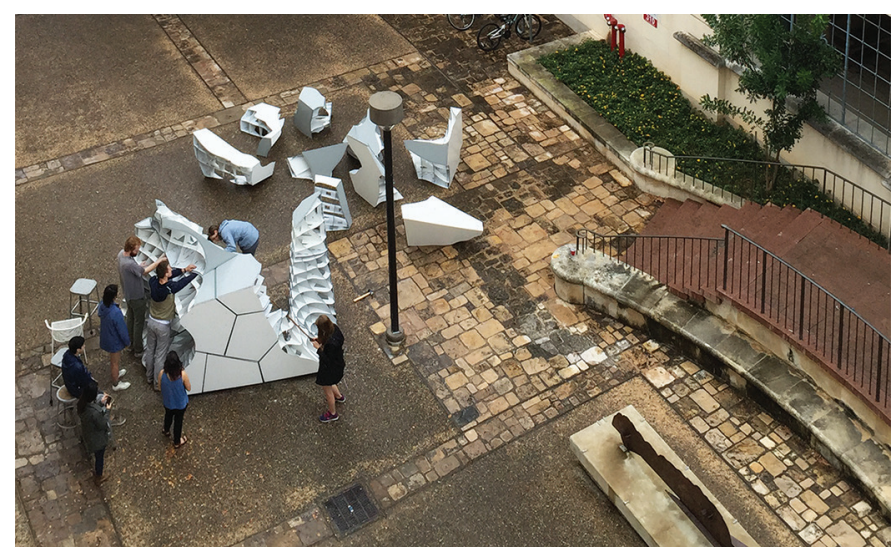

Figure 2: Assembly of Parts.

to a total system of meaning. ${ }^{\prime 9}$ In fact, it is in the relations between objects that the world truly unfolds and where architecture can insert itself into a milieu of other conditions either sympathetically, or violently. To do so violently would disrupt the existing stability of a place, causing a further retreat of each object into itself. To do so sympathetically would coax an even greater display of properties from other objects within the milieu.

$\mathrm{OOO}$ is not an anti-humanist philosophy. On the contrary, humans are just another part in the whole. As Levi Bryant argues, "humans are not excluded, but are rather objects among the various types of objects that exist or populate the world, each with their own specific powers and capacities." 10000 does not advocate an architecture without humans, but an architecture in which humans more fully engage with all of the other things that go into a building. It is the management of things in relation to people that an 000 approach to design can afford new opportunities for architecture to increase one's awareness of their environment.

\section{ORDERING SYSTEMS}

Every part to whole relation is guided by an ordering system. The ordering system is the glue that binds parts to whole. Parts may be bound loosely or tightly depending on how the system defines an object and what formula it uses to pattern the whole. In a reductionist ordering system, like swarm logic, the part to whole assembly is entirely relational. In this case, the whole is a summation of forces, capacities, and tendencies, while the parts within the whole are considered more or less the same. The properties intrinsic to each part are simply activated by their position and relation to the group.

The mechanistic uses an ordering system that is generated entirely by the parts and their ability to work together to form a whole. Bruno Latour describes "the relations among engine parts as forces between actors in a network - quasi-objects, which are neither human nor nonhuman...they each carry on fermenting their own plots, forming their own groups, and serving their own masters, wills and functions." 11 The parts are focused on their operation with one another, oblivious to that which exists outside the mechanically functioning whole.
Finally, the organicist (or parametricist) would, like a reductionist, favor the whole over the parts. They would acknowledge the physical dissimilarities that exist between parts, but the differences as they describe them would still be limited by factors imposed by the whole. This ordering system restricts a part's capacity to express novel behaviors or to become an altogether different object despite its potential to do so.

Gilles Deleuze and Felix Guattari addressed the parts to whole problem by introducing what they called the assemblage. In an assemblage, all things that are affecting are also affected by each other in a collective. The collective is any group of things that find themselves involved with one another and for some amount of time. Objects are constantly entering and exiting an assemblage, leaving the whole in a constant state of becoming (a term borrowed from Henri Bergson). Jane Bennett relates Deleuze's theory of the assemblage with 000 by stating that a whole is a "confederate agency of many striving macroand micro- actants: from 'my' memories, intentions, contentions, intestinal bacteria, eyeglasses, and blood sugar, as well as from the plastic computer keyboard, the bird song from the open window, or the air or particulates in the room, to name only a few of the participants. What is at work here...is an animal-vegetable-mineral-sonority cluster with a particular degree and duration of power. What is at work here is what Deleuze and Guattari call an assemblage."12

The difference between a machine and an assemblage, is that a machine works; it has a certain consistency and stability. An assemblage, on the other hand, is constantly undergoing de- and re-territorialization. It is in a state of constant transformation. A machine, if anything, is the catalyst to both affect change and to impart temporary stability to an otherwise entropic body. ${ }^{13}$ Christopher Alexander recognized that "stability...can only be understood as a product of interaction among parts. The essential character of anything, since it must at heart be based on some kind of stability, must be understood a product of interactions within the whole. When we view a thing in such a way as to reveal its character in holistic terms, we speak of it as a system." ${ }^{14} \mathrm{~A}$ whole that is dependent on the interaction of its parts, while also allowing for the uniqueness of each part to be expressed, shifts the organizational structure from one that is hierarchical to one that is systemic. Each object, though discrete, is part of the assemblage. The assemblage promotes specific instantiations of the part depending on the state of the system at any given moment: "Deleuze invented the notion of "adsorbsion" to describe this kind of part-whole relationship: adsorbsion is a gathering of elements in a way that both forms a coalition and yet preserves something of the agential impetus of each element." ${ }^{15}$

The capacity for an object to remain separate yet bound is a condition of its withdrawnness. In his book The Democracy of Objects, Levi Bryant argues that objects "in their virtual proper being, or not yet realized in the physical world, are withdrawn from any of their actualizations in local manifestations, nonetheless local manifestations are often highly constrained by the exo-relations an object enters into with other objects." ${ }^{16}$ Thus, every object that is realized in the physical 


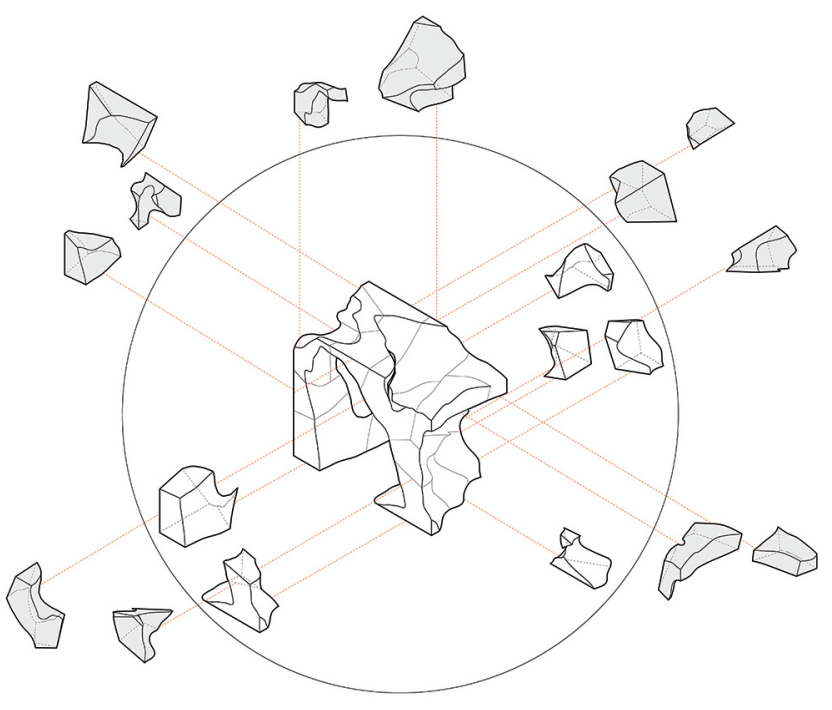

Figure 3: Exploded Diagram of Parts to Whole Assembly.

world is simply one manifestation from a range of alternatives that might have been, given different circumstances or other constraints imposed by neighboring objects.

Computation and digital design is an especially useful approach for architects interested in 000. By using scripting and other digital tools, architects can designs buildings in a way that they are semidetached from the process itself. That is, they are somewhat out-of-control of the design by using tools that can create things beyond their grasp (and one could argue, withdrawn from them). For example, scripting might start with a simple set of commands, but once those commands are run through an algorithm that introduces complexity, we end up with something that is inevitably new, or at least different from what we might have expected. Every iteration of an object is simply one version extricated from a large set of virtual possibilities.

\section{WATNEY: VIRTUAL PROPER BEING}

The goals of Watney were threefold. First, we have attempted to reevaluate a hierarchical structural scheme using a multi-directional waffle system. Second, we have sought to execute a flat ontology in which the project's parts exist as wholes in and of themselves. Third, we have aimed to create a cultural impact through Watney's relationship to its site and to one's experience, or interaction, with it.

Watney differs from most part-whole projects in that, while parts are implicated in a whole, the project lacks a hierarchical ordering system. The form was generated by a boolean between a solid and void and then divided into 21 parts differing in shape and size. The whole was divided in such a way that if parts were removed from the

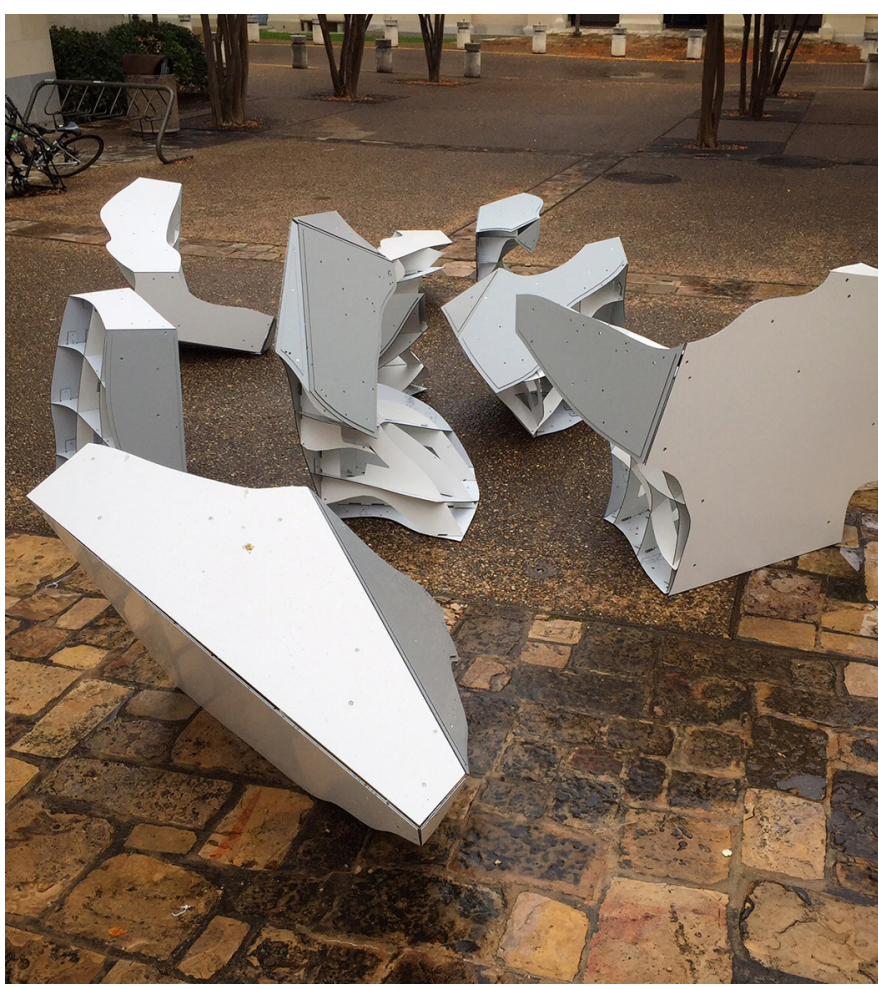

Figure 4: Assembled Parts with Internal Waffle and End Caps.

assembly, the project might look different, but would still perform the same way both structurally and spatially. The core of each part is a waffle system that stabilizes the piece. The direction of the internal waffle varies per part based on conditions that belong solely to the part. When parts are stacked in the assembly, the stress internal to each part is cancelled by the opposing forces in adjacent parts.

It is really the part to part connection logic that has true agency in the project. End-caps are secured to the waffle by teeth that hinge from the edge of each waffle rib. All teeth do not need to be used for the system to achieve stability, though their location must be known to adjoining parts in order to avoid conflicts during assembly. The connective strategy is non-hierarchical and shares an ordering system with the larger part whole assemblage by disentangling the parts (in this case the teeth) from a part to whole logic in which parts are subservient to the whole.

As Bennett notes, "Objects try to make sense of each other through the qualities and logics they possess. When one object caricatures another, the first grasps the second in abstract, enough for one to make some sense of the other given its own internal properties." ${ }^{17}$ Bennett refers to these loose contours between objects and points as the distributive agency of objects. There is a depth beyond the surface in which objects interact; it is a kind of murky surface that is not as defined as an object's outward form.

Bogost makes a similar claim by acknowledging that we (or any other object) will never know another object in its entirety. He notes that "when one object caricatures another, the first grasps the second in abstract, enough for one to make some sense of the other given its 


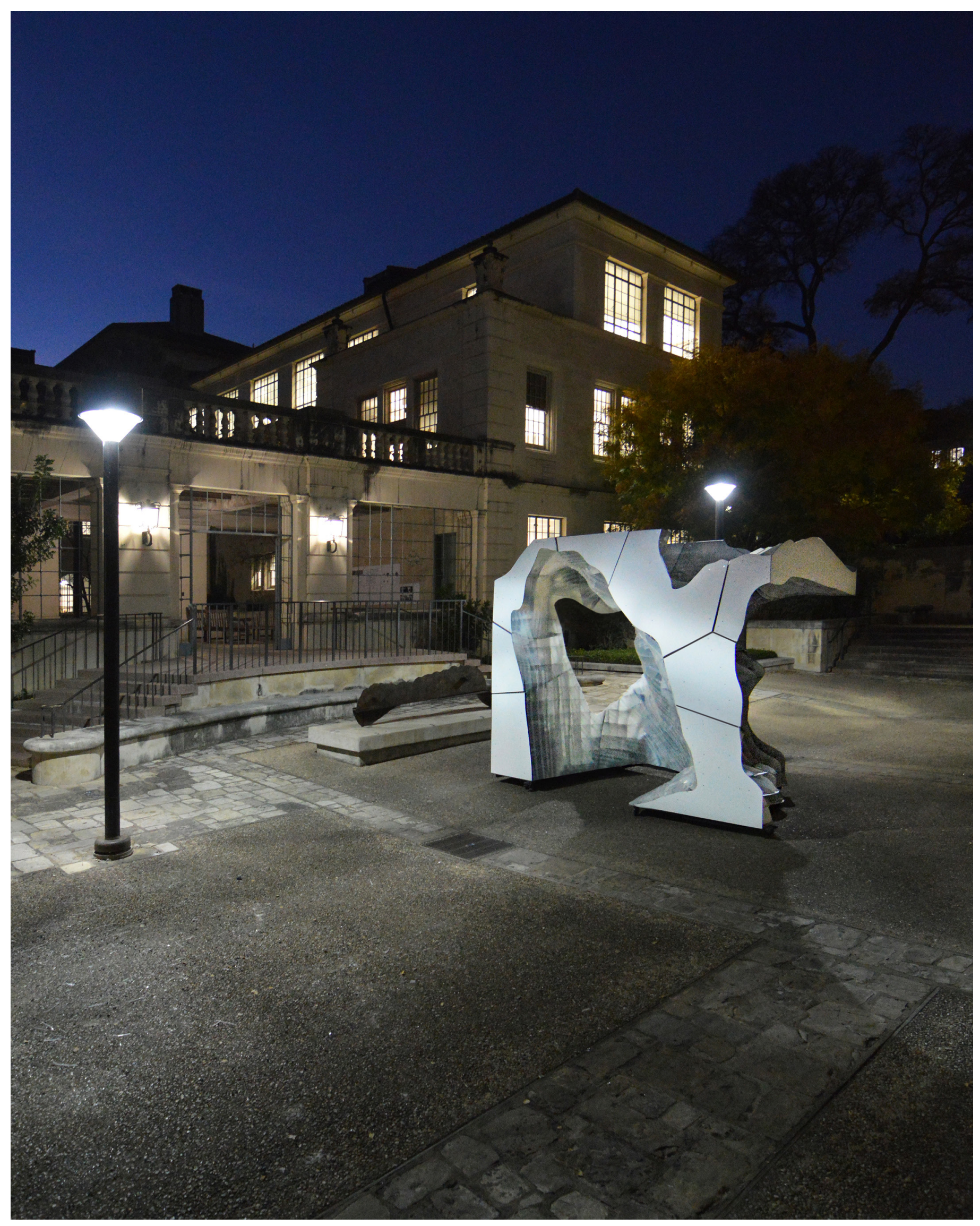

Figure 5: Watney at Night. 
own internal properties. A caricature is a rendering that captures some aspects of something else at the cost of other aspects."18 Each part has intrinsic properties that are not fully revealed to the other parts of the assemblage, but all properties are not withdrawn. Morton calls this the Rift: "There is a fissure between how we appear and what we are...The Rift guarantees that inner space, no matter how deep or vivid or sensitively attuned, is hermetically sealed from other entities." ${ }^{19}$ Every object expresses itself outwardly through an extrinsic set of properties that allow objects to relate to others through an ordering system that is non-hierarchical and dynamic.

\section{WATNEY: A CULTURAL OBJECT}

As architects, our job is to curate assemblies. In Watney, the assemblage is a group of objects that are affecting and being affected by the other objects as they transform over time. New objects enter while old objects exit, forming a dynamic architecture that is less about performance and more about constantly changing part whole relations.

Watney, as a whole, has a similar sort of agency to that occurring internally between parts, but outwardly, in the way it connects to the site, people, and other objects. Through its form, which includes windowlike portals, the object invites other objects (like people) by drawing them in and then once in establishing ways for them to view out from the project, framing the site in new ways. As Harman observes, "when I look at a far-off lighthouse, I am seeing it at a great distance-but at the same time it is also in direct, intimate contact with me, since I am occupied with seeing it. Any object that we encounter is de-severed: it is placed at a specific distance, but also brought directly and immediately into our explicit awareness." ${ }^{20}$ No matter what environment or context it is in, it is able to form relationships by affecting and being affected by the context. Through the lens of OOO, Watney's physical aggregation of parts in space, the site that contains it, and the individuals who view it, all participate in a very specific assemblage at a very specific time and place: "Society and nature do not form two separate and entirely distinct domains. Rather, collectives involving humans are always entangled with all sorts of nonhumans without which such collectives could not exist...object-oriented ontology draws our attention to these entanglements by placing the human and nonhuman on equal footing." ${ }^{21}$

As an attempt to build a new kind of cultural hyperobject, we applied an ordering system to Watney that puts all objects on equal footing. As designers we try to combine objects into assemblages, and projects that have the most potential to act on the world around them are those that maximally invite new relationships with other objects, including people, to enter and exit that assemblage. By designing a mobile installation that does not overlay conventional architectural typologies or programmatic needs to a form, the project invites people to discover what the project is by asking them to observe, occupy and think about it. This idea is reflected in the projects design. Watney is not just a superficial display of physical qualities and geometry, but an experiment in utilizing an emerging part-whole logic that questions the conventional role of form, structure, space, and meaning in architecture by eschewing a top-down, hierarchical ordering system.

\section{ENDNOTES}

1. Damon, Matt. The Martian. DVD. Directed by Ridley Scott. Los Angeles: Twentieth Century Fox, 2015.

2. Morton, Timothy. Hyperobjects: Philosophy and Ecology after the End of the World. Minneapolis: The University of Minnesota Press, 2013, 1.

3. Ibid, Morton, 7 .

4. Martin, Reinhold. "On Numbers, More or Less," in The Politics of Parametricism: Digital Technologies in Architecture, eds. Matthew Poole and Manuel Shvartzberg. London: Bloomsbury Publishing PIc, 2015, 54-55.

5. Harman, Graham. "On the Undermining of Objects: Grant, Bruno, and Radical Philosophy," in The Speculative Turn: Continental Materialism and Realism, eds. Levi Bryant, Nick Srnicek, and Graham Harman. Melbourne: Re.press, 2011, 25.

6. Gage, Mark Foster. "Killing Simplicity: Object-Oriented Philosophy In Architecture," in Log 33. 2015, 99.

7. Descartes, Rene, and Thomas Steele Hall. Treatise on Man. Cambridge: Harvard University Press, 1972, 108.

8. Bogost, lan. Alien Phenomenology, or, What it's like to be a Thing. Minneapolis: The University of Minnesota Press, 2012, 17.

9. Harman, Graham. Heidegger Explained: From Phenomenon to Thing. Chicago: Open Court, 2007, 1.

10. Bryant, Levi R. The Democracy of Objects. Ann Arbor: Open Humanities Press, 2011, 20.

11. Ibid, Bogost, 76 .

12. Bennett, Jane. Vibrant Matter: A Political Ecology of Things. Durham: Duke University Press, 2010, 23

13. Delueze, Gilles, and Felix Guattari. A Thousand Plateaus: Capitalism and Schizophrenia. Minneapolis: The University of Minneapolis Press, 1987, 333.

14. Harman, Graham. Heidegger Explained: From Phenomenon to Thing. Chicago: Open Court, 2007, 1.

15. Ibid, Bennett, 50 .

16. Ibid, Bryant, 196.

17. Ibid, Bennett, 89 .

18. Ibid, Bogost, 66 .

19. Ibid, Morton, 196.

20. Ibid, Harman, 65.

21. Ibid, Harman, 25. 